\title{
Synthesis and catalytic applications of ultrasmall Copper Nanoparticles using Aloe vera plant extract
}

\author{
Rajagopal Ramkumar*, Shradha Sapru, Panthalattu Parambil Archana \\ Department of Organic Chemistry, Indian Institute of Science, Bangalore-560012, India \\ E-mail: cy19ipf01@smail.iitm.ac.in
}

Dedicated to Professor Srinivasan Chandrasekaran on the occasion of his 75th birthday

\begin{abstract}
An extract of Aloe Vera acts as a powerful reducing agent for the synthesis of ultrasmall copper nanoparticles (CUNPs) in water medium. The prepared copper nanoparticles are characterized by XRD, HRTEM and UV-Vis analysis. The diameter of the prepared nanoparticle is less than $5 \mathrm{~nm}$. The catalytic activity of CuNPs has been successfully evaluated for the three-component reaction to synthesize 1,2,3-triazoles and chalcone tethered 1,2,3-triazoles with low catalyst loading and under mild reaction conditions. These triazoles are further utilized for the synthesis of dihydropyrazines.
\end{abstract}

KEYWORDS: Ultrasmall nanoparticle, Copper nanoparticles, Aloe Vera extract, Triazoles, Pyrazine

\section{Introduction:}

1,2,3-triazoles are important structural moieties in pharmaceutical products due to their biological properties ${ }^{1}$ and are useful in many industries involved in dyes, photostabilizers, photographic materials and agrochemicals. ${ }^{2}$ The synthesis of 1,2,3-triazoles is generally achieved by using Huisgen cycloaddition reaction of azides with terminal alkynes. ${ }^{3}$ However, this methodology produces a mixture of 1,4- and 1,5-disubstituted products using substrates having a strong electron-withdrawing substituent either on the azide or on the alkyne. ${ }^{4}$ The regioselective synthesis of 1,4-disubstitued triazole was achieved by Meldal ${ }^{5 a}$ and Sharpless ${ }^{5 b}$ with the reaction of azides and terminal alkynes in the presence of Copper(I)-catalyst under mild conditions.

Nowadays, much attention has been paid to the use of nanoparticles as catalysts in synthetic organic chemistry ${ }^{6}$ due to the availability of more active reactive sites and the control of reaction rates. ${ }^{7}$ In general, many copper based catalysts have been employed for the 1,3-dipolar cycloaddition reaction of azides and alkynes ${ }^{8}$ because of advantages of lower cost and ready availability. In recent years, there is growing interest in the use of hetero-bimetallic copper nanoparticles, alumina supported copper nanoparticles, $\mathrm{Cu} / \mathrm{Cu}$-oxide nanoparticles and $\mathrm{Cu}$ nanoclusters as catalysts for the 1,3-dipolar cycloaddition of azides to terminal alkynes. ${ }^{9}$ All the above mentioned copper nanoparticles require special equipment and reaction conditions for preparation and use. Herein, we report the synthesis of ultrasmall copper nanoparticles using Aloe Vera plant extract for reduction, which turns out to be a simple, lowcost, low-energy and low-hazard aqueous synthetic method, and its use for the synthesis of 1,4- triazoles.

\section{Results and Discussion:}

Aloe Vera extract was prepared based on the reported procedure for preparing lemongrass extract used in the synthesis of ultrasmall copper nanoparticles. ${ }^{10}$ This extract was then used to synthesise $\mathrm{Cu}_{2} \mathrm{O}$ nanoparticles, using $\mathrm{Cu}(\mathrm{OAc})_{2} \cdot \mathrm{H}_{2} \mathrm{O}$ as the precursor copper salt. The asprepared $\mathrm{Cu}_{2} \mathrm{O}$ nanoparticles obtained from the Aloe Vera 


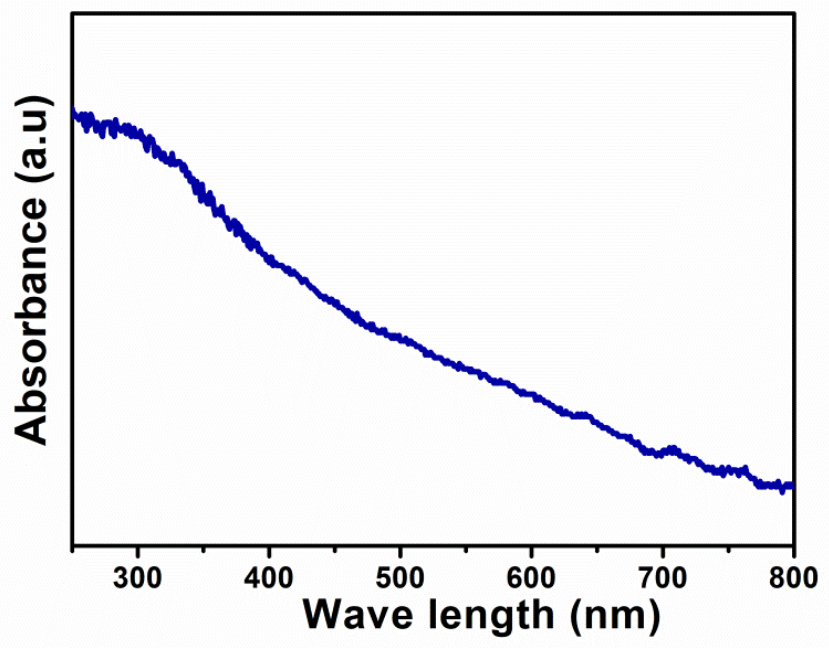

Figure 1: UV-visible spectrum of as-prepared $\mathrm{Cu}_{2} \mathrm{O}$ nanoparticles.

extract were dispersed in ethanol and the UV-visible spectrum was acquired. Figure 1 shows the UV-visible spectrum of $\mathrm{Cu}_{2} \mathrm{O}$ nanoparticles, which did not exhibit any characteristic band as the spectrum was very broad and featureless. The absence of surface plasmon resonance peaks in the visible spectrum (Figure 1) confirms that the diameter of the copper nanoparticles is less than $5 \mathrm{~nm} .{ }^{11}$

Further, $\mathrm{Cu}_{2} \mathrm{O}$ NPs obtained were characterized using powder XRD technique and the powder XRD pattern is shown in Figure 2. The powder XRD pattern of as-prepared $\mathrm{Cu}_{2} \mathrm{O}$ nanoparticles exhibited four characteristic peaks at 2-theta values of $36.4^{\circ}, 42.2^{\circ}, 61.3^{\circ}$ and $73.5^{\circ}$ which correspond to the (111), (200), (220) and (311) planes respectively, and these crystallographic planes could be assigned to the cubic phase of $\mathrm{Cu}_{2} \mathrm{O}$ (JCPDS \# 05-0667).

In addition, the as-prepared $\mathrm{Cu}_{2} \mathrm{O}$ nanoparticles were analysed using TEM, which is shown in Figure 3. The BFTEM image (Figure 3a) revealed that the as-prepared sample consisted of well separated and spherical $\mathrm{Cu}_{2} \mathrm{O}$ nanoparticles which are embedded in an organic matrix. The size of the $\mathrm{Cu}_{2} \mathrm{O}$ nanoparticles was found to be in the range of 2- 5 $\mathrm{nm}$. The HRTEM image (Figure $3 \mathrm{~b}$ ) shows the lattice fringes, and d-spacing measured from the two consecutive planes of a particle was found to be $2.08 \AA$. The measured d-spacing value matched with the (111) plane of cubic-Cu nanoparticles. Figure 3c shows the histogram of particle size distribution of $\mathrm{Cu}_{2} \mathrm{O}$ nanoparticles with a mean diameter of $3.7 \mathrm{~nm}$ and standard deviation of $0.9 \mathrm{~nm}$.

Having characterised the catalyst, we were interested to study the catalytic activity of $\mathrm{Cu}_{2} \mathrm{O}$ nanoparticles for the CuAAC reaction for the synthesis of 1,2,3-triazoles. Benzyl bromide (1 mmol) (Scheme 1) was subjected to the threecomponent reaction with $\mathrm{NaN}_{3}(1.2 \mathrm{mmol})$ and terminal alkynes ( $1 \mathrm{mmol})$ using $\mathrm{Cu}_{2} \mathrm{O}$ nanoparticles as catalyst at room temperature (in ethanol). This led to the formation of triazoles 3a-e in $89-96 \%$ yield. The alkynes containing either electron-donating or withdrawing substitutions on the aryl ring offer the corresponding triazoles $\mathbf{3 b} \mathbf{b}-\mathbf{d}$ in good yield. Ethyl propiolate also reacts very smoothly, leading to the formation of the desired product $\mathbf{3 e}$ in high yield.

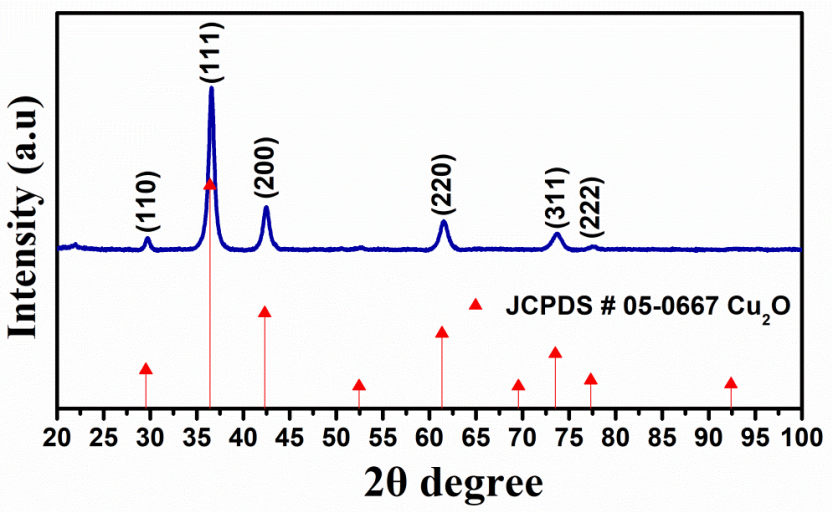

Figure 2. Powder XRD pattern of $\mathrm{Cu}_{2} \mathrm{O}$ nanoparticles prepared from Aloe Vera extract as a reducing agent.
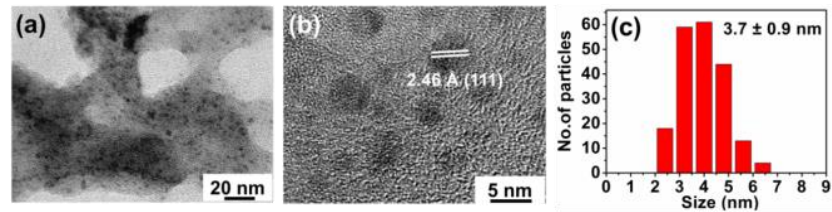

Figure 3. Morphological characterization of $\mathrm{Cu}_{2} \mathrm{O}$ nanoparticles: (a) BFTEM image; (b) HRTEM image and (c) Particle size distribution.

At this stage, we decided to study the reactivity of various structurally and electronically different azides with terminal alkynes in ethanol (Scheme 2). Our initial studies with tosyl azide (1 mmol) and phenylacetylene $(1.2 \mathrm{mmol})$ in ethanol gave $93 \%$ of 1,2,3-triazole (5a). The reaction of different azides with various terminal alkynes was explored in ethanol at room temperature and the results are presented in Scheme 2. The reaction generally yielded the expected products (5a-e) in good yields.
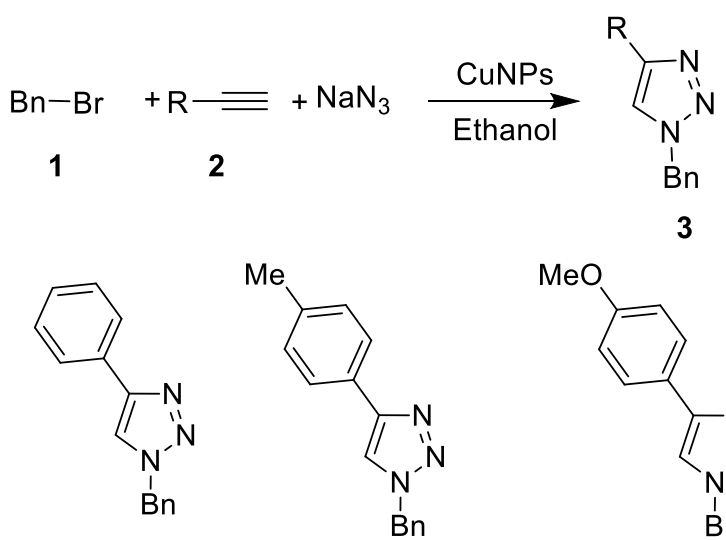

3

3a; $94 \%$

3b; $96 \%$

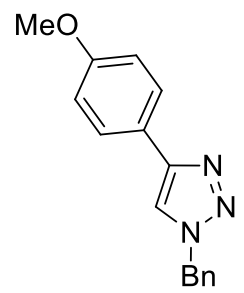<smiles>Brc1ccc(-c2cn(Cc3ccccc3)nn2)cc1</smiles><smiles>CCOC(=O)c1cn(Cc2ccccc2)nn1</smiles>

3d; $89 \%$

3e; $90 \%$

Scheme 1. Three-component 1,3-dipolar cycloaddition reaction catalysed by ultrasmall CuNPs. 

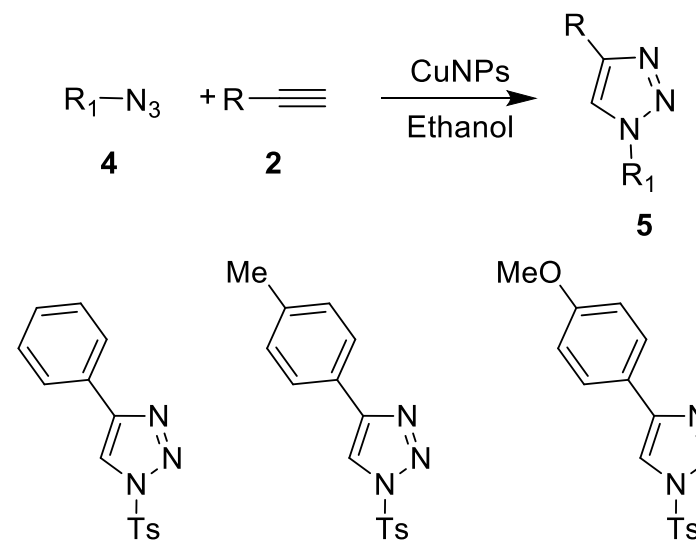

5a; $93 \%$
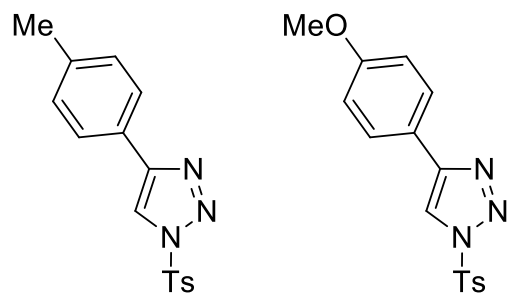

5b; $89 \%$

5c; $91 \%$
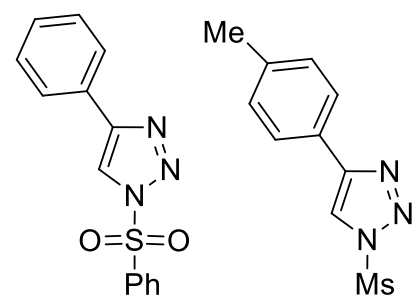

5d; $94 \%$

5e; $91 \%$

Scheme 2. Ultrasmall CuNPs catalysed 1,3-dipolar cycloaddition of azides and alkynes.

It was of interest to study the reaction of chalcone tethered alkynes (10) with $\mathrm{TsN}_{3}$ using $\mathrm{Cu}_{2} \mathrm{O}$ nanoparticles in triethylamine and THF under nitrogen atmosphere. The chalcone tethered alkynes (10) were prepared by the propargylation of 2-hydroxybenzaldehyde (6) using $\mathrm{K}_{2} \mathrm{CO}_{3}$ and catalytic amount of TBAI in DMF as solvent at room temperature. Further, aldol condensation of the 0-alkylated benzaldehyde (8) and 4-methylacetophenone (9) in the presence of $\mathrm{KOH}$ in ethanol produced the corresponding chalcone tethered alkynes (10) (Scheme 3) ${ }^{12}$ The alkyne (10) (1.0 equiv) was stirred with CuNPs in $5 \mathrm{ml}$ of THF for $3 \mathrm{~min}$ at room temperature, followed by the addition of $\mathrm{TsN}_{3}$ (1.3 equiv) in one-pot, with continued stirring for additional $12 \mathrm{hrs}$ at room temperature to afford 11a-c in moderate yields (Scheme 3).

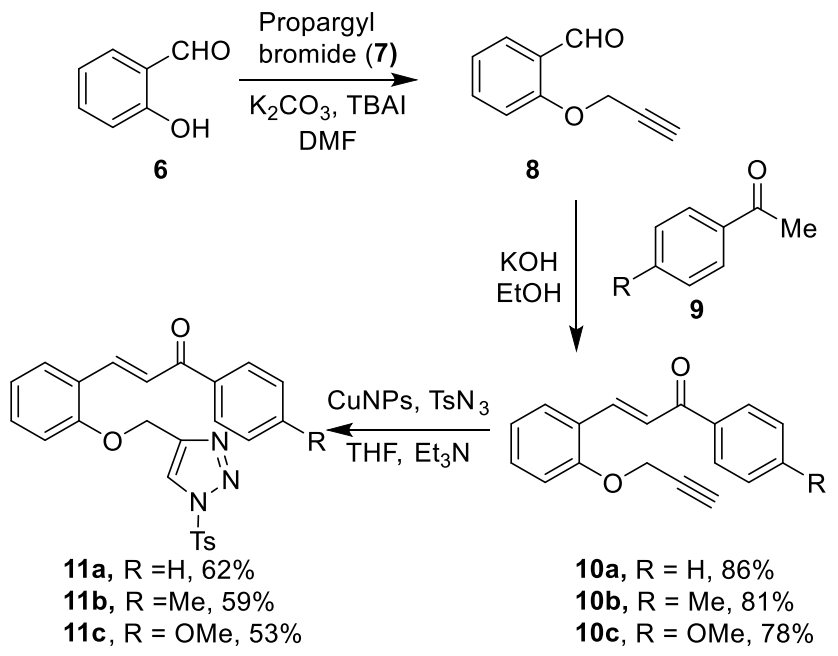

Scheme 3. Synthesis of chalcone tethered 1,2,3-triazoles using CuNPs.

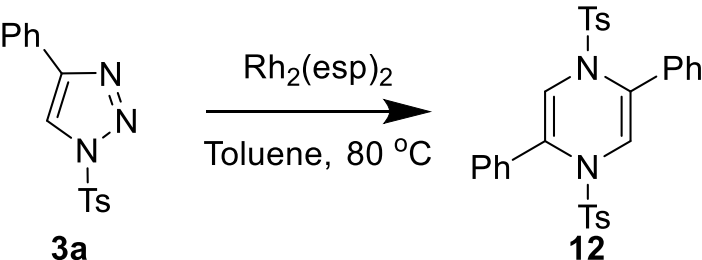

Scheme 4. Synthetic utility of synthesised 1,2,3-triazoles.

Further, we interested to test the reactivity of 1 -sulfonyl 1,2,3-triazole 3a with rhodium(II)-catalyst (Scheme 4). Triazole 3a undergoes a dimerization reaction involving the insitu generation of azavinyl carbene to form compound 12.

Conclusion: Ultrasmall $\mathrm{Cu}_{2} \mathrm{O}$ nanoparticles have been easily synthesised from copper acetate monohydrate using Aloe Vera extract as a reducing agent. These $\mathrm{Cu}_{2} \mathrm{O}$ nanoparticles are found to catalyse a three component 1,3-dipolar cycloaddition reaction of azides and alkynes in ethanol at room temperature. Additionally, the $\mathrm{Cu}_{2} \mathrm{O}$ nanoparticles were also used for the synthesis of chalcone tethered triazoles. The catalyst could be recycled and reused for further reactions. The synthesised triazoles were utilised for further synthetic transformations.

\section{Experimental Section}

Materials: $\mathrm{Cu}(\mathrm{OAc})_{2} \cdot \mathrm{H}_{2} \mathrm{O}$ was purchased from Spectrochem. Ltd., India. Absolute ethanol (HPLC grade, 99.9\%), Ethylacetate, Hexanes were obtained from S.D. Fine Chemicals Ltd., India. Silica gel 230 - 400 mesh, was purchased from Sisco Research Laboratories Pvt. Ltd., India. Deionised water was used for purification process. All glassware were thoroughly dried in a hot air oven prior to use.

Measurements: The bright-field transmission electron microscopy (BFTEM) images, high resolution transmission electron microscopy (HRTEM) images were obtained using a JEOL JEM-2100F microscope operating at an accelerating voltage of $200 \mathrm{kV}$. TEM specimens were prepared by dispersion of powders in ethanol and deposited on Formvar coated copper grids. UV-visible absorption spectrum was collected at room temperature using a Perkin Elmer Lambda 700 UV-vis-near-IR spectrophotometer with a double monochromator. Powder X-ray diffraction data were collected on a PANalytical Empyrean X-ray diffractometer using $\mathrm{Cu} \mathrm{K \alpha}(0.154 \mathrm{~nm})$ radiation, at $45 \mathrm{kV}$ and 30 mA. ${ }^{1} \mathrm{H}$ NMR spectra were recorded on a Bruker Avance at $400 \mathrm{MHz}$ using $\mathrm{CDCl}_{3}$ or DMSO-d 6 in ppm $(\delta)$ related to TMS $(\delta=0.00)$ as an internal standard and are reported as follows; chemical shift (ppm), multiplicity (br = broad, $\mathrm{s}=$ singlet, $\mathrm{d}=$ doublet, $\mathrm{m}=$ multiplet), coupling constant $(\mathrm{Hz})$ and integration. ${ }^{13} \mathrm{C}$ NMR spectra were recorded at 100 $\mathrm{MHz}$ in $\mathrm{CDCl}_{3}$ or DMSO- $\mathrm{d}_{6}$. Chemical shifts are reported in delta $(\delta)$ units, parts per million (ppm) relative to the centre of the triplet at $77.7 \mathrm{ppm}$ for $\mathrm{CDCl}_{3}$ or $39.5 \mathrm{ppm}$ for DMSO- $\mathrm{d}_{6}$. Carbon types were determined from ${ }^{13} \mathrm{C}$ NMR and DEPT experiments. Mass spectra were measured with Micromass Q-Tof (ESI-HRMS). Thin layer chromatography was performed on SILICA GEL GF-254 and components were visualized by observation under iodine/UV light at $254 \mathrm{~nm}$. 
Preparation of Aloe Vera leaf extract: Aloe Vera leaves were taken and washed thoroughly with deionised water. The ends of the leaves were chopped off and the leaves were cut into small pieces. ${ }^{10}$ The pieces of Aloe Vera leaves (50 g) were added to $80 \mathrm{~mL}$ of deionized water. The mixture was allowed to boil at $80^{\circ} \mathrm{C}$ for 30 minutes. This was then allowed to cool to room temperature $\left(25^{\circ} \mathrm{C}\right)$. The mixture was then filtered and the filtrate was stored in the refrigerator at $4^{\circ} \mathrm{C}$. The extract prepared was used as the Aloe Vera leaf extract for subsequent reactions.

Synthesis of copper oxide $\left(\mathrm{Cu}_{2} \mathrm{O}\right)$ nanoparticles: A solution of $\mathrm{Cu}(\mathrm{OAc})_{2} . \mathrm{H}_{2} \mathrm{O}(5 \mathrm{mmol})$ was prepared with deionised water $(20 \mathrm{ml})$. Aloe Vera leaf extract $(20 \mathrm{ml})$ was then added to this solution. The above mixture was stirred for about $6 \mathrm{hrs}$ at $80^{\circ} \mathrm{C}$. After the reaction time elapsed, the mixture was allowed to cool down to room temperature. The precipitate (CuNPs) was obtained through vacuum filtration, followed by washing it with deionised water twice and then air drying it.

General Procedure for three-component synthesis of 1,2,3-triazoles with $\mathrm{Cu}_{2} \mathrm{O}$ NPs as catalyst: Alkyl halide (1.0 mmol), $\mathrm{NaN}_{3}(1.5 \mathrm{mmol})$, alkyne $(1.2 \mathrm{mmol})$ and $\mathrm{Cu}_{2} \mathrm{O}$ NPs (5 mol \%) were placed in a flask equipped with a magnetic stirring bar containing $2 \mathrm{~mL}$ of ethanol under air atmosphere and stirred. The reaction was continued for the appropriate time mentioned. After completion of the reaction, the reaction mixture was worked up by addition of water $(25 \mathrm{~mL})$ and extracted with ethylacetate (2x25 $\mathrm{mL}$ ).After drying the organic extract using anhydrous $\mathrm{Na}_{2} \mathrm{SO}_{4}$, it was concentrated under reduced pressure. The residue was purified using column chromatography on silica gel.

Synthesis of 1,2,3-triazoles from Azides and Alkynes using $\mathrm{Cu}_{2} \mathrm{O}$ NPs as a Catalyst: Alkyl azide (1.0 mmol), alkyne (1.2 mmol) and $\mathrm{Cu}_{2} \mathrm{O} \mathrm{NPs}(5 \mathrm{~mol} \%)$ were placed in a flask equipped with a magnetic stirring bar containing 2 $\mathrm{mL}$ of ethanol under air atmosphere. The reaction mixture was stirred for the appropriate time mentioned. After completion of the reaction, the reaction mixture was concentrated and the residue was purified using column chromatography on silica gel.

Procedure for Synthesis of Chalcone tethered 1,2,3triazole using $\mathrm{Cu}_{2} \mathrm{O}$ NPs: Chalcone tethered alkyne (1 mmol), alkyl azide $(1.3 \mathrm{mmol})$, triethyl amine $(1 \mathrm{mmol})$ and $\mathrm{Cu}_{2} \mathrm{O}$ NPs (5 mol \%) were placed in a flask equipped with a magnetic stirring bar containing $5 \mathrm{~mL}$ of THF under a nitrogen atmosphere. The reaction mixture was stirred for the appropriate time mentioned. After completion of the reaction, the reaction mixture was concentrated and the residue was purified using column chromatography.

\section{Acknowledgements}

The authors are grateful to Professor Srinivasan Chandrasekaran of the Department of Organic Chemistry, IISc Bangalore, India for his suggestions and manuscript corrections. R.R. thanks the University Grants Commission, India for a fellowship under Dr. D. S. Kothari Postdoctoral Scheme (No. CH/14-15/0132). S.S. thanks the IASc-INSANASI India for a summer research fellowship (No. CHES857). P.A. thanks IISc Bangalore, for allowing her to work for a Summer Project.

\section{Author Contributions}

S.S. performed the preparation of CuNPs and synthesis. P.A. performed the synthetic studies of chalcone tethered triazole and their applications. R.R. monitored and performed the preparation of CuNPs and synthesis.

\section{Supporting Information}

Copies of ${ }^{1} \mathrm{H}$ and ${ }^{13} \mathrm{C}$ NMR spectra of all the compounds.

\section{AUTHOR INFORMATION \\ ORCID \\ Rajagopal Ramkumar: 0000-0002-3811-9707 \\ Shradha Sapru: 0000-0001-9712-2335 \\ Corresponding Author \\ *Email: cy19ipf01@smail.iitm.ac.in}

\section{Notes}

The authors declare no competing financial interest.

\section{REFERENCES}

1. (a) R. Alvarez, S. Velazquez, A. San-felix, S. Aquaro, E. De Clercq, C-.F. Perno, A. Karlsson, J. Balzarini, M. J. Camarasa J. Med. Chem., 1994, 37, 4185-4194. (b) S. Velazquez, R. Alvarez, C. Perez, F. Gago, C. De Clercq, J. Balzarini, M. J. Camarasa, Antiviral Chem. Chemother., 1998, 9, 481-489 (c) M. J. Genin, D. A. Allwine, J. Anderson, M. R. Barbachyn, D. E. Emmert, S. A. Garmon, D. R. Graber, K. C. Grega, J. B. Hester, D. K. Hutchinson, J. Morris, R. J. Reischer, C. W. Ford, G. E. Zurenko, J. C. Hamel, R. D. Schaadt, D. Stapert, B. H Yagi J. Med. Chem., 2000, 43, 953-970. (d) P. Thirumurugan, D. Matosiuk, K. Jozwiak Chem. Rev. 2013, 113, 4905-4979. (e) K. Bozorov, J. Zhao, H. A. Aisa Bioorg Med Chem. 2019, 27, 3511-3531.

2. W.-Q. Fan, A. R. Katritzky 1,2,3-Triazoles. In Comprehensive Heterocyclic Chemistry II; Katritzky, A. R., Rees, C. W., Scriven, E. F. V., Eds.; Elsevier Science: Oxford, U.K., 1996; Vol. 4, pp 1-126.

3. (a) P. Huisgen Pure Appl. Chem., 1989, 61, 613-628. (b) R. Huisgen, G. Szeimies, L. Moebius Chem. Ber., 1965, 98, 4014-4021.

4. (a) V. D. Bock, H. Hiemstra, J. H. van Maarseveen, Eur. J. Org. Chem., 2006, 51-68. (b) M. Meldal, C. W. Tornøe, Chem. Rev., 2008, 108, 2952-3015. (c) P. Appukkuttan, E. Van der Eycken, Eur. J. Org. Chem., 2008, 1133-1155. (d) C. O. Kappe, E. Vander Eycken Chem. Soc. Rev., 2010, 39, 1280-1290. (e) J. E. Moses, A. D. Moorhouse, Chem. Soc. Rev., 2007, 36, 12491262. (f) H. Nandivada, X. Jiang and J. Lahann, $A d v$. Mater., 2007, 19, 2197-2208. (g) J.-F. Lutz Angew. Chem. Int. Ed. 2007, 46, 1018-1025. (h) A. Dondoni, Chem. Asian J. 2007, 2, 700-708. (i) A. D. Moorhouse, J. E. Moses, ChemMedChem 2008, 3, 715-723. (l) K. Kacprzak, I. Skiera, M. Piasecka, Z. Paryzek, Chem. Rev. 2016, 116, 5689-5743.

5. (a) C. W. Tornøe, C. Christensen, M. Meldal, J. Org. Chem., 2002, 67, 3057-3064. (b) V. V. Rostovtsev, L. 
G. Green, V. V. Fokin, K. B. Sharpless, Angew. Chem., Int. Ed. 2002, 41, 2596-2599.

6. (a) U. Gulati, U. C. Rajesh, D. S. Rawat. ACS Sustainable Chem. Eng., 2018, 6, 10039-10051. (b) F. Alonso, Y. Moglie, G. Radivoy, Acc. Chem. Res., 2015, 48, 2516-2528. (c) R. Bayan, N. Karak, ACS Omega, 2017, 2, 8868-8876. (d) C. Xu, R. A. D. Arancon, J. Labidi, R. Luque, Chem. Soc. Rev., 2014, 43, 74857500.

7. (a) Selective Nanocatalysts and Nanoscience, 1st ed.; A. Zecchina, S. Bordiga, E. Groppo, Eds.; Wiley-VCH: Weinheim, Germany, 2011. (b) Nanomaterials in Catalysis; P. Serp, K. Philippot, Eds.; Wiley-VCH: Weinheim, Germany, 2013.

8. (a) L. Liang, D. Astruc, Coord. Chem. Rev., 2011, 255, 2933-2945. (b) M. Meldal, C.-W. Tornøe, Chem. Rev., 2008, 108, 2952-3015. (c) B. Dervaux, F. E. Du Prez, Chem. Sci., 2012, 3, 959-966. (d) T. Jin, M. Yan, Y. Yamamoto, ChemCatChem., 2012, 4, 1217-1229. (e) T. Nakamura, T. Terashima, K. Ogata, S.-I. Fukuzawa, Org. Lett., 2011, 13, 620-623.

9. (a) K. Kaneda, K. Ebitani, T. Mizugaki, K. Mori, Bull. Chem. Soc. Jpn., 2006, 79, 981-1016. (b) B. H. Lipshutz, B. R. Taft, Angew. Chem. Int. Ed., 2006, 45, 8235-8238. (c) C.-T. Lee, S. Huang, B. H. Lipshutz, Adv. Synth. Catal., 2009, 351, 3139-3142. (d) S. Chassaing, A. S. S. Sido, A. Alix, M. Kumarraja, P. Pale, J. Sommer, Chem. Eur. J., 2008, 14, 6713-6721; b) S. Chassaing, A. Alix, T. Boningari, K. S. S. Sido, M. Keller, P. Kuhn, B. Louis, J. Sommer, P. Pale, Synthesis 2010, 1557-1567.

10. (a) A. D. Brumbaugh, K. A. Cohen, S. K. St. Angelo, ACS Sustainable Chem. Eng., 2014, 2, 1933-1939. (b) H. L. $\mathrm{Tu}$, Composite Materials, 2019, 3, 30-35.

11. (a) S. A. Masurkar, P. R. Chaudhari, V. B. Shidore, S. P. Kamble, Nano-Micro Lett., 2011, 3, 189-194. (b) M. Singh, I. Sinha, M. Premkumar, A. K. Singh, R. K. Mandal, Colloid Surf., A 2010, 359, 88-94. (c) O. P. Siwach, P. J. Sen, Nanopart. Res., 2008, 10, 107-114. (c) M. P. Pileni, I. Lisiecki, Colloids Surf., A 1993, 80, 63-68.

12. Y.-S. Zhang, X.-Y. Tang, M. Shi, Chem. Commun., 2014, 50, 15971-15974. 